\title{
Automated morphometry of corneal endothelial cell: use of video camera and video tape recorder
}

\author{
OKIHIRO NISHI AND KOICHI HANASAKI \\ From the Nishi Eye Hospital, 4-14-26 Nakamichi, Higashinari-ku, Osaka, and the Faculty of Engineering of \\ Kyoto University, Yoshida Honmachi, Sakyo-ku, Kyoto, Japan
}

SUMMARY We developed an apparatus for automated morphometry of the corneal endothelium, which was photographed through a specular microscope connected to a video camera, and the images were stored on a video tape. The clearest stationary image was input into an image analyser to determine automatically the cell boundaries. Although human interaction is generally necessary, the mean time required to complete this procedure was about 13 minutes, based on the results of the 30 normal eyes, and the time needed for manual correction was about 4 minutes. The mean cell area obtained by this method correlated well $(\mathrm{r}=0.9335)$ with that obtained by tracing the same images. This apparatus is clinically useful for immediately obtaining the mean cell area of corneal endothelium and will extend the application of specular microscopy to the routine clinical setting.

Morphometry of corneal endothelial cells, which include an analysis of mean cell areas, cell shapes, and cell densities, is now recognised as being indispensable for the evaluation of corneal function in many clinical situations. ${ }^{1-7}$ This morphometric analysis is carried out with a digitiser ${ }^{x-11}$ or an image analyser." II In these methods the cell boundaries must be determined by marking the apices of the endothelial cells or by tracing the original photographic image. These tedious and time consuming procedures must be performed manually, increasing the chance of errors. Moreover, since the methods involve photography, there is room for further errors in the enlargement process, and the photographic procedures involved in taking pictures, development, and enlargement require considerable time and labour. To overcome these problems automated techniques of endothelial cell morphometry have been designed by which cell boundaries are determined automatically and directly on the original photograph with an image analyser..$^{1:-17}$

We previously reported ${ }^{17}$ a method of processing images on $35 \mathrm{~mm}$ negative film by inputting them directly into an image analyser for automatic cell boundary determination, and achieved considerable economy of time and energy. However, all attempts at automated morphometry have faced a common

Correspondence to DrO Nishi problem: the cell images that are commonly obtained in clinical settings are often not distinct enough for completely automated determination of cell boundaries owing to lack of clarity and interference by cell contents such as the nucleus, and they require manual correction. Therefore obtaining clear cell images more frequently and efficiently, making accurate image correction during the analysing process, as well as improving the algorithm of image processing, are critical matters for the routine clinical utilisation of data obtained by endothlial cell morphometry.

From these considerations we developed a more labour and time saving technique employing a video camera (VC) and a video tape recorder (VTR), by which endothelial cell boundaries are automatically determined, and mean cell area as well as cell density are obtained immediately after video-recording.

\section{Material and methods}

APPARATUS

A clinical specular microscope (Konansha, CSP580) mounted with $a \times 50$ objective lens was connected to a VC (NEC, TI-22AII), and the images obtained were recorded with a VTR (Sony, U-Matic VO $5800)$. The clearest images were selected during slow playback, and time base errors were corrected with a digital time base corrector (For-A, FA-400). 


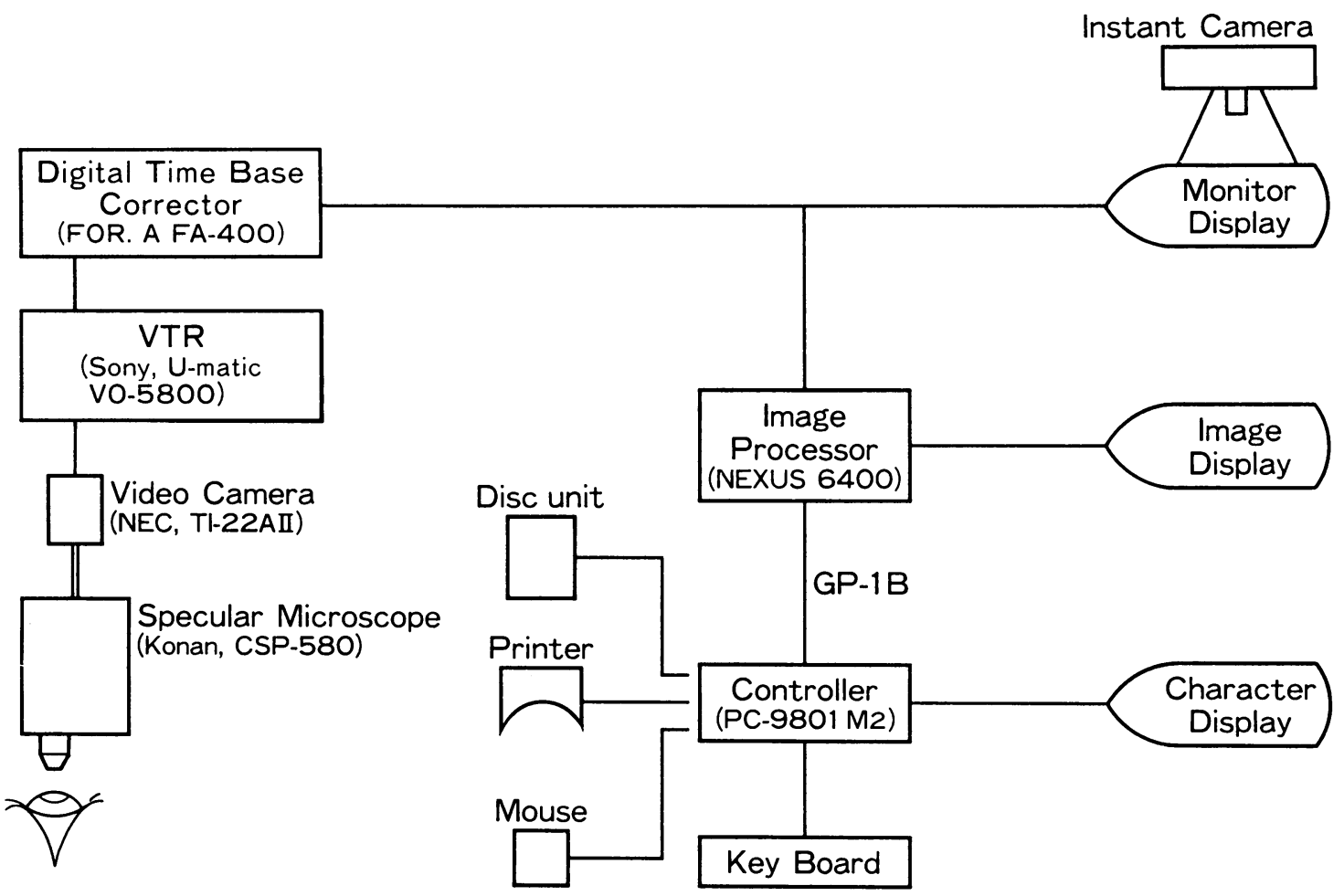

Fig. 1 Block diagram of the aparatus.

Stationary images are obtained with its single-frame function, input into an image analyser (NEXUS, 6400 ), and processed with a microcomputer (NEC, pc-9801M2) (Fig. 1).

\section{ALGORITHM FOR DETERMINATION OF CELL} BOUNDARIES

Unprocessed VTR images are input (Fig. 2) and stacked 10-20 times.

Shading compensation of images. High frequency noise is excluded with a $3 \times 3$ pixels grid, and differences in brightness among portions of the image are

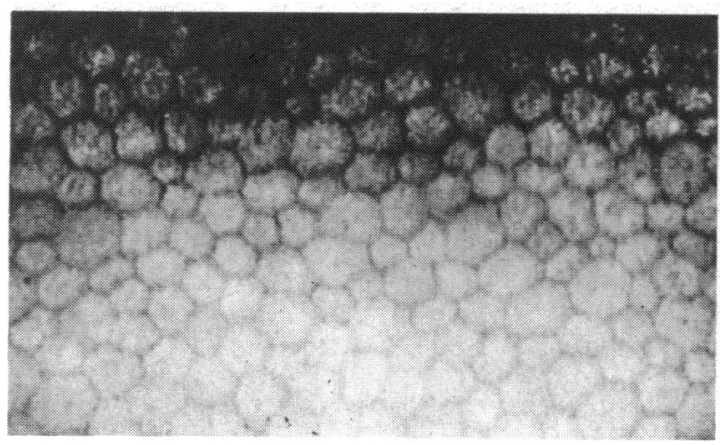

Fig. 2 The unprocessed image of endothelial cells in a single memory VTR frame. minimised with a $15 \times 15$ pixels grid. The compensated images obtained are subtracted from the original image to produce an image in which the cell boundaries are enhanced (Fig. 3).

Binary representation. The enhanced images obtained are converted to binary representation (0 for the dark cell boundary and 1 for the bright cell interior).

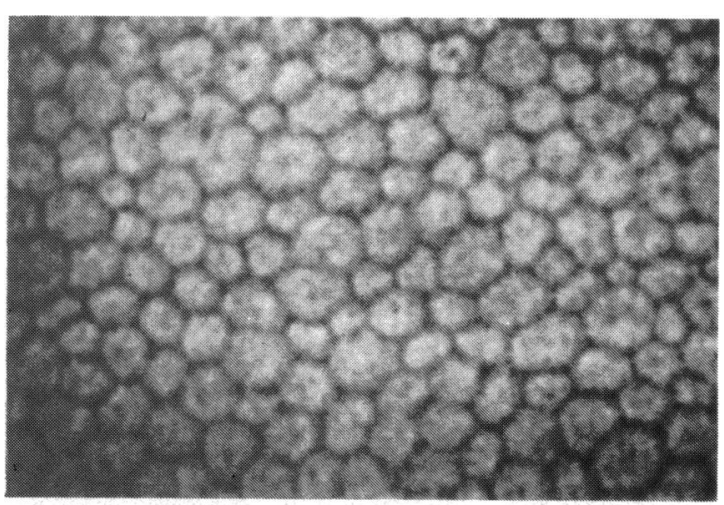

Fig. 3 Image in which the cell boundaries are enhanced after elimination of high frequency noise, subtraction of the original image from the smoothed image obtained by reducing the difference in brightness. 


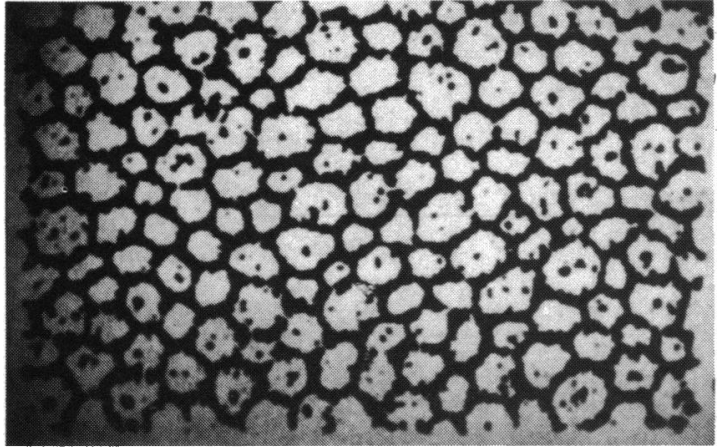

Fig. 4 Final binary image.

The area of the image to be analysed is determined by arbitrarily placing a frame. The maximum and minimum thresholds are determined from the brightness histogram of the image. Binary images are prepared serially from the maximum to the minimum threshold, and the image considered to be optimal is selected (Fig. 4), so that any binary image between the maximum and the minimum threshold can be reproduced, or the entire binary conversion process can be performed again. Since the quality of the final image is greatly dependent on the determination of the optimal threshold values, these steps are extremely important for accurate judgment.

Restoration of cell boundaries. Since the shape of the cell is more or less distorted in the binary image, the original cell morphology is restored by processes such as hole filling, edge detection, removal of small particles, and removal of small particles from the outer circumference. Further, an entire cell image surrounded by a boundary can be deleted (Fig. 5).

Correction of images. Cells may be still fused or defects may be present in the cell images obtained by the above procedure. Such cells are corrected with the digitizer while overlapping the original image. Defects are filled by adding lines or planes, using a

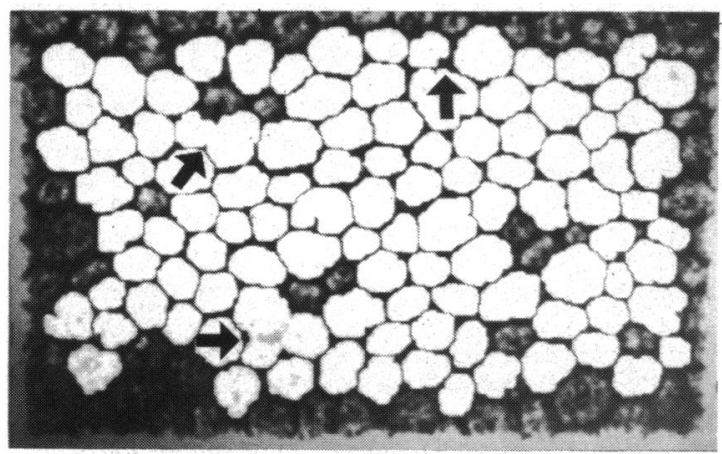

Fig. 5 Image after overlapping of the original image. Arrows show defects and fusion of cell images.

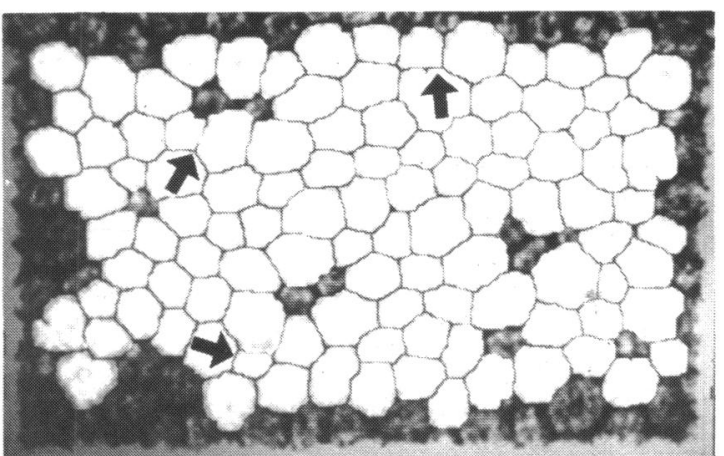

Fig. 6 Image shown in Fig. 5 after correction. Defects are filled and fused cells are separated (arrows).

line thickness of 2 pixels, and the size of the drawing can be freely adjusted. The boundary between fused cell images is drawn similarly with a line 2 pixels in thickness (Fig. 6).

Thinning of cell boundaries. Since the boundaries between cells are still thick and irregular, the width of the boundary is reduced to 1 pixel (Fig. 7).

Labelling and measurement. This process is performed by the routine program of the image analyser.

\section{SUBJECTS}

The central area of the corneal endothelium of 30 normal eyes in 15 subjects (age 22-65 years) was photographed (f $1 / 2$ ) for 20-30 seconds with the specular microscope and recorded in the VTR.

The accuracy of measurement was examined by comparing the mean endothelial cell area of each eye determined directly from the VTR images with that determined from the traced images of the same cells displayed on the video monitor and photographed with an instant camera.

The computer was programmed to calculate the time required for each of the image processing stages, and the time needed for the entire procedure and correction of images was determined.

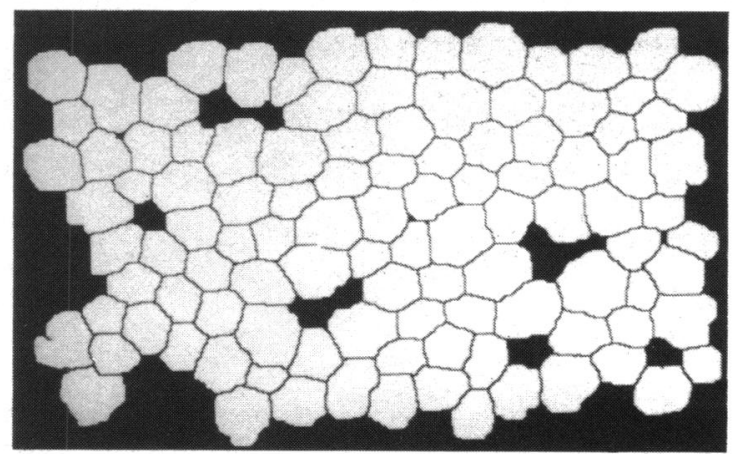

Fig. 7 Final image after reduction of the width of the cell boundary to 1 pixel. 
Table 1 VTR image analysis

\begin{tabular}{|c|c|c|c|c|c|c|}
\hline Patient & Sex & Age & $\begin{array}{l}\text { Mean cell } \\
\text { area }(Y) \\
\left(\mu m^{2} \pm S D\right)\end{array}$ & $\begin{array}{l}\text { No. of } \\
\text { cells } \\
\text { analysed }\end{array}$ & $\begin{array}{l}\text { Time required } \\
\text { for entire } \\
\text { procedure } \\
\text { (min) }\end{array}$ & $\begin{array}{l}\text { Time required } \\
\text { for manual } \\
\text { correction } \\
\text { (min) }\end{array}$ \\
\hline \multirow[t]{2}{*}{1} & $F$ & 21 & $342 \pm 130$ & 77 & $15 \cdot 2$ & $6 \cdot 8$ \\
\hline & & & $353 \pm 85$ & 83 & $14 \cdot 1$ & $6 \cdot 2$ \\
\hline \multirow[t]{2}{*}{2} & $\mathbf{F}$ & 22 & $339 \pm 88$ & 69 & $13 \cdot 4$ & $4 \cdot 5$ \\
\hline & & & $331 \pm 96$ & 84 & $11 \cdot 3$ & $3 \cdot 8$ \\
\hline \multirow[t]{2}{*}{3} & $\mathbf{F}$ & 23 & $323 \pm 88$ & 99 & $9 \cdot 5$ & 0 \\
\hline & & & $336 \pm 92$ & 101 & $10 \cdot 4$ & 0 \\
\hline \multirow[t]{2}{*}{4} & F & 23 & $341 \pm 84$ & 88 & $9 \cdot 3$ & 0 \\
\hline & & & $335 \pm 91$ & 92 & $9 \cdot 8$ & 0 \\
\hline \multirow[t]{2}{*}{5} & F & 26 & $359 \pm 109$ & 86 & 17.9 & $9 \cdot 0$ \\
\hline & & & $361 \pm 130$ & 67 & $18 \cdot 2$ & $7 \cdot 3$ \\
\hline \multirow[t]{2}{*}{6} & $\mathbf{F}$ & 24 & $355 \pm 122$ & 81 & 14.9 & $7 \cdot 8$ \\
\hline & & & $350 \pm 129$ & 70 & $16 \cdot 8$ & $4 \cdot 0$ \\
\hline \multirow[t]{2}{*}{7} & $\mathbf{M}$ & 36 & $388 \pm 88$ & 75 & $16 \cdot 2$ & $6 \cdot 2$ \\
\hline & & & $393 \pm 96$ & 84 & $15 \cdot 2$ & $6 \cdot 4$ \\
\hline \multirow[t]{2}{*}{8} & $\mathbf{M}$ & 30 & $367 \pm 103$ & 88 & $12 \cdot 9$ & 0 \\
\hline & & & $355 \pm 101$ & 114 & $15 \cdot 2$ & $4 \cdot 8$ \\
\hline \multirow[t]{2}{*}{9} & $\mathbf{M}$ & 54 & $391 \pm 112$ & 98 & $11 \cdot 5$ & 0 \\
\hline & & & $386 \pm 103$ & 106 & $12 \cdot 2$ & $3 \cdot 0$ \\
\hline \multirow[t]{2}{*}{10} & $\mathbf{M}$ & 64 & $405 \pm 103$ & 76 & $14 \cdot 3$ & $6 \cdot 5$ \\
\hline & & & $417 \pm 111$ & 71 & $15 \cdot 7$ & 7.9 \\
\hline \multirow[t]{2}{*}{11} & $\mathbf{F}$ & 28 & $362 \pm 84$ & 101 & $12 \cdot 3$ & $3 \cdot 5$ \\
\hline & & & $350 \pm 88$ & 104 & $12 \cdot 7$ & 3.9 \\
\hline \multirow[t]{2}{*}{12} & $\mathbf{F}$ & 24 & $346 \pm 88$ & 62 & $12 \cdot 2$ & 0 \\
\hline & & & $351 \pm 89$ & 54 & $13 \cdot 9$ & $3 \cdot 3$ \\
\hline \multirow[t]{2}{*}{13} & $\mathrm{~F}$ & 24 & $332 \pm 108$ & 97 & $16 \cdot 5$ & $6 \cdot 3$ \\
\hline & & & $340 \pm 118$ & 91 & $18 \cdot 0$ & $7 \cdot 4$ \\
\hline \multirow[t]{2}{*}{14} & $\mathbf{F}$ & 23 & $323 \pm 93$ & 98 & $11 \cdot 3$ & $3 \cdot 5$ \\
\hline & & & $336 \pm 101$ & 94 & $9 \cdot 2$ & $2 \cdot 2$ \\
\hline \multirow[t]{2}{*}{15} & $F$ & 21 & $330 \pm 90$ & 101 & $11 \cdot 5$ & $2 \cdot 3$ \\
\hline & & & $326 \pm 88$ & 98 & $10 \cdot 0$ & 0 \\
\hline Mean & & & & $87 \pm 14$ & $13 \cdot 3 \pm 2 \cdot 7$ & $3.9 \pm 2.9$ \\
\hline
\end{tabular}

\section{Results}

The regression equation between the mean cell area determined directly from the VTR images (Y) (Table 1) and that determined from the trace of the same image displayed on the monitor $(\times 200)$ and photographed with an instant camera (X) (Table 2) was $\mathrm{Y}=0.7190 \mathrm{X}+96 \cdot 5, \mathrm{r}=0.9335$ (Fig. 8).

The mean time required for the entire procedure in all subjects was 13.3 (SD 2.7) minutes. The mean time for correction was 3.9 (SD 2.9) minutes. The number of cells analysed was 55-114 cells, mean 87 (SD 14). The number of completely automated analyses was 8 of the 30 eyes $(27 \%)$.

\section{Discussion}

Our system eliminates the need for conventional photographic procedures by directly analysing VTR images, thus making cell morphometry possible immediately after taking a picture. This enables considerable economy of time and labour. Another advantage of the technique is that 10-20-second VTR film always includes at least a few very clear cell images.
Table 2 Analysis of trace of same VTR image

\begin{tabular}{lc}
\hline Mean cell area $(X)$ & No. of cells analysed \\
\hline $361 \pm 126$ & 81 \\
$363 \pm 87$ & 85 \\
$347 \pm 92$ & 83 \\
$340 \pm 101$ & 90 \\
$314 \pm 116$ & 104 \\
$321 \pm 97$ & 110 \\
$336 \pm 84$ & 80 \\
$325 \pm 86$ & 82 \\
$385 \pm 113$ & 99 \\
$374 \pm 126$ & 55 \\
$372 \pm 102$ & 75 \\
$358 \pm 120$ & 65 \\
$399 \pm 146$ & 67 \\
$412 \pm 101$ & 79 \\
$371 \pm 121$ & 70 \\
$376 \pm 111$ & 109 \\
$386 \pm 98$ & 86 \\
$398 \pm 118$ & 99 \\
$415 \pm 101$ & 80 \\
$436 \pm 128$ & 76 \\
$353 \pm 91$ & 90 \\
$361 \pm 86$ & 85 \\
$322 \pm 99$ & 80 \\
$343 \pm 92$ & 72 \\
$326 \pm 106$ & 88 \\
$352 \pm 128$ & 86 \\
$335 \pm 95$ & 89 \\
$329 \pm 92$ & 92 \\
$327 \pm 95$ & 97 \\
$311 \pm 97$ & 114 \\
\hline &
\end{tabular}

Hartmann et al. ${ }^{16}$ recently reported on an automated cell morphometry system using a frame memory mechanism. This method does not require the process of recording the images in VTR for subsequent analysis. Further, the signal-to-noise ratio may be higher than that of the VTR because of the digital memory system. However, as the number of frames is limited to 256, the recording time is short, and hence skilful timing is required for photographing the human eye, which is constantly moving.

On the other hand our images are recorded in the VTR. This allows a long recording time with serial exposures every $1 / 30$ second, so that well focused and clear images of the living eyes can be readily obtained. The resolution may be reduced, which necessitates the process of selecting suitable images and inputting them into the image analyser, but these processes are simple and require only a short time.

The accuracy of an analyser in detecting cell boundaries is a matter of the greatest concern in developing automated cell morphometric techniques. Our results showed a satisfactory correlation $(\mathrm{r}=0.9335)$ (Fig. 8) with those obtained by a tracing method using the same image data, indicating that our method can be used in the clinical setting.

The number of cells analysed by this technique was smaller (mean 87 (SD 14)) (Table 1) than that by the 
Fig. 8 Linear regression equation | between the mean cell area determined by direct automated analysis of VTR image $(Y)$ and that determined by the trace of the same image.

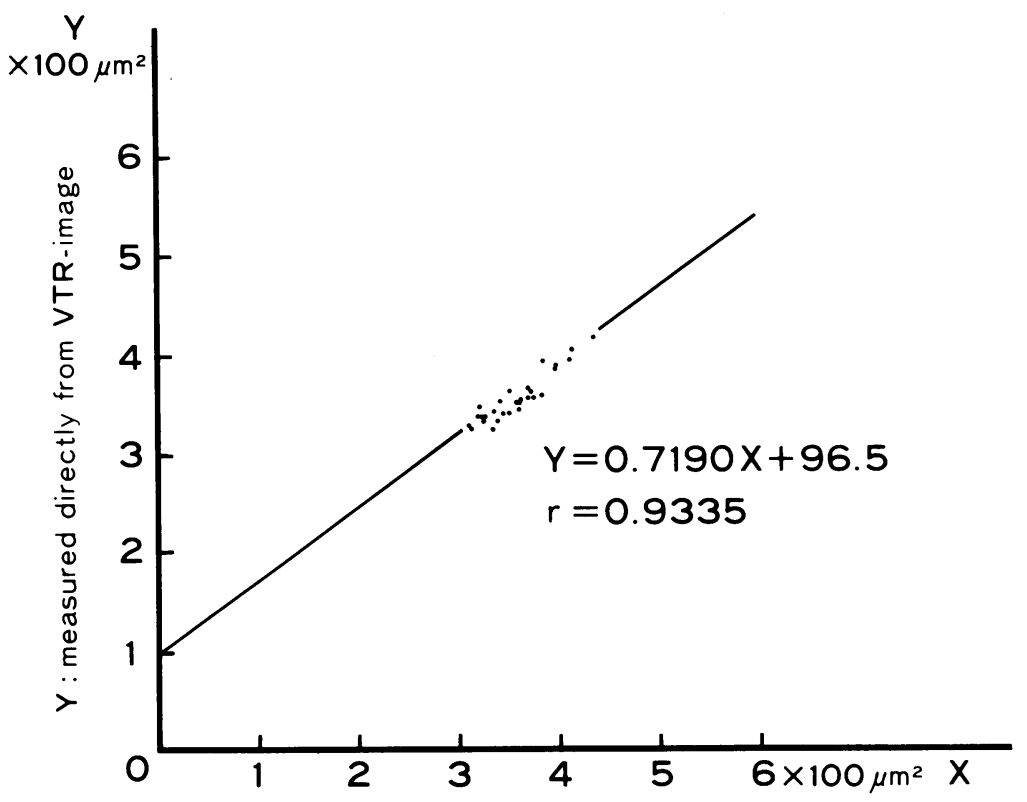

$X$ : measured from the traced micrograph of the same VTR-image tracing method (120-150), ${ }^{18-21}$ because the aperture was usually set at $f 1 / 2$ to obtain a deep focus and because the cells that required extensive correction were eliminated in the stage of binary conversion by setting the thresholds high. Theoretically, analysis of all cell images input into the image analyser is possible when using such a threshold. An increase in the number of cell images inputted, however, will result in an increase in the number of images with incomplete boundaries, prolongation of correction and determination time, and decrease in accuracy. Thus the number of cells analysed is primarily dependent on the quality of the original image but secondarily on the time needed for, and accuracy of, its correction. To achieve a reasonable balance among these factors - that is, to determine the threshold to be used for binary conversion and how much correction should be made to obtain adequate accuracy of the data-experienced human judgment while monitoring the image on the display is still indispensable. So we think that analysis of 50 to 120 cells, or at most 150 cells, is a sufficient number to assess corneal function in routine clinical use, for example, for quickly determining the orientation prior to intraocular lens implantations. By our technique, as well as other automated systems for cell morphometry, cell boundaries are determined by the computer, but the operator must always confirm whether it detected all boundaries correctly. Therefore completely automated systems in the true sense of the word will be realised only after the development of more sophisticated techniques.

All the currently available systems require human judgment in determining the optimal threshold and image correction in reference to the original image. However, our apparatus achieved reasonable accuracy in data processing, requiring slightly more than 10 minutes for completion of the entire procedure. The part of the procedure involving human interaction does not need excessive concentration by the operator. Therefore this technique appears to be suitable for routine clinical use.

\section{References}

1 Matsuda N, Suda T, Manabe R. Serial alterations in endothelial cell shape and pattern after intraocular surgery. $\mathrm{Am} J$ Ophthalmol 1984; 98: 313-9.

2 Schults RO, Matsuda M, Yee RW, Edelhauser HF, Schults KJ. Corneal endothelial changes in type I and type II diabetes mellitus. Am J Ophthalmol 1984; 98: 401-10.

3 Rao GH, Waldon WR, Aquavella JV. Morphology of graft endothelium and donor age. Br J Ophthalmol 1980; 64: 523-7.

4 Matsuda M, Bourne WM. Long-term morphologic changes in the endothelium of transplanted corneas. Arch Ophthalmol 1985; 103: 1343-6.

5 Matsuda M, Suda T, Manabe R. Quantitative analysis of endothelial mosiac pattern changes in anterior keratoconus. $\mathrm{Am}$ J Ophthalmol 1984; 98: 43-9.

6 Karai I, Matsumura S, Takise S, Horiguchi S, Matsuda M. Morphological change in the corneal endothelium due to ultraviolet radiation in welders. Br J Ophthalmol 1984; 68: 544-8.

7 Glasser DB, Matsuda M, Ellis JG, Edelhauser HF. Effects of 
irrigating solutions on the corneal endothelium after in vivo anterior chamber irrigation. Am J Ophthalmol 1985; 99: 321-8.

8 Laing RA, Sandstrom MM, Berrospi AR, Lcibowitz HM. Changes in the corneal endothelium as a function of age. Exp Eye Res 1976; 22: 587-94.

9 Waring GO, Krohn MA, Ford GE, Harris RR, Rosenblatt HL. Four methods of measuring human corneal endothelial cells from specular photomicrographs. Arch Ophthalmol 1980; 98: 848-55.

10 Nishi $\mathrm{O}$, Hanasaki K. Corneal endothelial damage following cataract surgery and intraocular lens implantation. Jpn J Clin Ophthalmol 1983; 37: 13-7.

11 Sato T. Studies on the endothelium of the corneal graft. Jpn J Ophthalmol 1978; 22: 114-26.

12 Shaw EL, Rao GN, Arthur EJ, Aquavella JV. The functional reverse of corneal endothelium. Ophthalmology 1978; 85: 640-9.

13 Lester JM, McFarland JL, Bursell SE, Laing RA, Brenner JF. Automated morphometric analysis of corneal endothelial cells. Invest Ophthalmol Vis Sci 1981; 20: 407-10.

14 Hartmann C, Weingart M, Dünner P, Giraud JP. Automatisierte endothelmorphometrie. 1982; 79: 261-5.

15 Hirst LW, Sterner RE, Grant DG. Automated analysis of wide- field specular photomicrographs. Cornea $1984 ; 3: 83-7$.

16 Hartmann C, Köditz W. Automated morphometric endothelial analysis combined with video specular microscopy. Cornea 1985 3: $155-67$.

17 Nishi O. Direct measurement of the corneal endothelial cell area on the negative film. Nippon Ganka Gakkai Zasshi 1985; 89: $1120-4$.

18 Sawa M, Tanishima T. The morphometry of the human corneal endothelium and follow-up of postoperative changes. Jpn J Ophthalmol 1979; 23: 337-50.

19 Inoda S, Ohkubo A, Tatsui T, Ohara K. Topographical Morphometry of the human corneal endothelium using new parameters. Folia Ophthalmol Jpn 1983; 34: 1002-9.

20 Kandori T, Sawa M, Tanishima T. Computerized morphometry of the human corneal endothelium. Nippon Ganka Gakkai Zasshi 1981; 85: 1204-7.

21 Komine T, Oikawa T. Analysis of specular photomicrography with a computerized digitizer and an image analyzer. Nippon Ganka Gakkai Zasshi 1981; 85: 457-63.

Accepted for publication 13 November 1986. 